\title{
Injection of biosurfactant and chemical surfactant following hot water injection to enhance heavy oil recovery
}

\author{
Yahya Al-Wahaibi ${ }^{1}$ Hamoud Al-Hadrami ${ }^{1}$ - Saif Al-Bahry ${ }^{2}$ - Abdulkadir Elshafie ${ }^{2}$. \\ Ali Al-Bemani ${ }^{1} \cdot$ Sanket Joshi $^{2}$
}

Received: 6 November 2014/Published online: 10 December 2015

(C) The Author(s) 2015. This article is published with open access at Springerlink.com

\begin{abstract}
This study investigates the potential of enhancing oil recovery from a Middle East heavy oil field via hot water injection followed by injection of a chemical surfactant and/or a biosurfactant produced by a Bacillus subtilis strain which was isolated from oil-contaminated soil. The results reveal that the biosurfactant and the chemical surfactant reduced the residual oil saturation after a hot water flood. Moreover, it was found that the performance of the biosurfactant increased by mixing it with the chemical surfactant. It is expected that the structure of the biosurfactant used in this study was changed when mixed with the chemical surfactant as a probable synergetic effect of biosurfactant-chemical surfactants was observed on enhancing oil recovery, when used as a mixture, rather than alone. This work proved that it is more feasible to inject the biosurfactant as a blend with the chemical surfactant, at the tertiary recovery stage. This might be attributed to the fact that in the secondary mode, improvement of the macroscopic sweep efficiency is important, whereas in the tertiary recovery mode, the microscopic sweep efficiency matters mainly and it is improved by the biosurfactantchemical surfactant mixture. Also as evidenced by this study, the biosurfactant worked better than the chemical surfactant in reducing the residual heavy oil saturation after a hot water flood.
\end{abstract}

Yahya Al-Wahaibi

ymn@squ.edu.om

1 Petroleum and Chemical Engineering Department, Sultan Qaboos University, 112 Muscat, Oman

2 Department of Biology, College of Science, Sultan Qaboos University, 112 Muscat, Oman

Edited by Yan-Hua Sun
Keywords Hot water injection - Biosurfactant - Chemical surfactant $\cdot$ Enhanced oil recovery

\section{Introduction}

In the oil industry, biosurfactants are used for enhancing oil recovery, bioremediation, dispersion, and transfer of crude oils (Gautam and Tyagi 2005; Lee et al. 2007). These biosurfactants are complex molecules comprising different structures which include lipopeptides, phospholipids, glycolipids (such as rhamnolipids, trehalose lipids, and sophorolipids), fatty acids, and neutral lipids (Gautam and Tyagi 2005).

A Bacillus subtilis strain C9 from the Korean Collection for Type Cultures (KCTC) was found to produce biosurfactants that lowered the surface tension of water from 72 to $28.5 \mathrm{mN} / \mathrm{m}$ and proved to be stable under various ranges of salinity and $\mathrm{pH}$. There are other $B$. subtilis strains that produced lipopeptide biosurfactants, similar to surfactins or lichenysins, such as $B$. subtilis strain C-1, B. subtilis strain PTCC 1696 (Ghojavand et al. 2008), five different Bacillus strains (Joshi and Desai 2013), and the surfactin ATCC 6633 produced by a $B$. subtilis strains which is one of the most powerful biosurfactants that reduces the surface tension of water from 72 to $27.9 \mathrm{mN} / \mathrm{m}$ (Noudeh et al. 2005; Gautam and Tyagi 2005).

The extraction of crude biosurfactant from the grown microbial broth depends on its ionic charge, water solubility, and location (intracellular, extracellular, or cell bound). There are many recovery methods available such as acetone precipitation, solvent extraction, acid precipitation, and crystallization (Gautam and Tyagi 2005). The most widely used technique in batch mode process is extraction with chloroform-methanol, dichloromethane- 
methanol, butanol, or acetic acid, which are relatively expensive solvent-based methods. In contrast, the acid precipitation method is comparatively inexpensive and reported for extraction of lipopeptide biosurfactant like surfactin, where lipopeptide biosurfactants that are not soluble under highly acidic conditions $(\mathrm{pH} 2.0-4.0)$ are precipitated (Makkar and Cameotra, 1997).

There are various experiments at laboratory scale using sand-pack columns or corefloods and field trials that have proved the effectiveness of using biosurfactants for microbial enhanced oil recovery (MEOR). Lichenysin produced by Bacillus licheniformis strain JF-2 showed residual oil recovery from cores up to $40 \%$. Similarly, four different strains of Pseudomonas showed over $50 \%$ recovery of crude oil at $70{ }^{\circ} \mathrm{C}$ in saturated sand-pack experiments. Although chemically synthesized surfactants have long been used in the petroleum industry, they are commonly environmentally toxic and not biodegradable. Biosurfactants have the benefit of being biodegradable and relatively inexpensive. However, there are some limitations which reduce the attractiveness of using biosurfactants widely in petroleum field applications. These limitations include the quantity and quality of the biosurfactants compared to chemical surfactants in addition to scale up complications in producing large amounts of biosurfactants for field applications as biosurfactants are generally produced in small amounts even at an industrial level. However, the discovery of new biosurfactants and development of new fermentation and recovery processes may allow more biosurfactants to be used for MEOR (Torres et al. 2011; Joshi and Desai 2013). This paper reports the ability of the biosurfactant produced by B. subtilis strain W19 to enhance oil recovery by interaction in porous media using original rock and fluid samples from an Omani oil field in coreflood experiments. In addition, the possibility of enhancing the performance of the biosurfactant for oil recovery by mixing it with commercially available chemical surfactants that are used in the Omani oil fields is investigated. Different mixture solutions are prepared at ratios of 25:70, 50:50, and 75:25 of the biosurfactant to the chemical surfactant, respectively. The mixing is done to better prove the applicability of biosurfactant for enhancing oil recovery by increasing its performance by adding chemical surfactants.

Surfactant loss due to adsorption is a major limitation during a surfactant flood for enhancing oil recovery since it causes surfactant retention which affects the economical feasibility of this process. Excessive surfactant retention results in adverse phase behavior properties, which cause the mobilized oil to be trapped again (Daoshan et al. 2004). This study includes adsorption analysis to quantify the amount of biosurfactant adsorbed in milligrams per gram of solid or crushed rocks. This was done to assess the applicability of using this biosurfactant for enhancing oil recovery and comparing its adsorption tendency to that of the commercially available chemical surfactants.

Al-Sulaimani et al. (2010, 2011a, b, 2012) and Al-Bahry et al. $(2013 \mathrm{a}, \mathrm{b})$ reported that the biosurfactant had potential for enhancing oil recovery since it yielded a total production of $23 \%$ of residual oil. In this study, possibility of enhancing the oil recovery from a Middle East heavy oil field by biosurfactant following hot water injection was investigated. Additionally, the biosurfactant performance was compared with the performance of a commercially available chemical surfactant. Previous studies reported that biosurfactants could potentially be used in conjunction with synthetic surfactants to provide more cost-effective enhanced oil recovery and subsurface remediation (Daoshan et al. 2004). The economic efficiency of biosurfactants depends on the use of low cost raw materials, such as molasses or cheese whey, which account for $10 \%-$ $30 \%$ of the overall cost (Joshi et al. 2008). Portwood (1995) reviewed hundreds of projects and concluded that the cost of MEOR process, including biosurfactants, ranges from $\$ 0.25$ to $\$ 0.50$ per barrel of oil produced and does not go up as oil production increases. A more recent study reported that the price of biosurfactants ranges between US\$ 2 and 3 per $\mathrm{kg}$ (Hazra et al. 2011). It was reported that the reduction in interfacial tension (IFT) by the surfactants has to be ultra low, where the IFT values should be in the range of $10^{3} \mathrm{mN} / \mathrm{m}$, to enhance oil recovery by increasing the capillary number (Aoudia et al. 2006; Curbelo et al. 2007; Zhu et al. 2009; Iglauer et al. 2010; Lu et al. 2014a, $\mathrm{c}, \mathrm{d})$. Although the minimum IFT value obtained by the biosurfactant in this study is not ultra low, other recovery mechanisms are expected to take place.

Recently, wettability alteration has been proposed as one of the mechanisms of MEOR where several studies reported the relation between IFT reduction and alteration of wetting conditions following microbial treatment (Sayyouh et al. 1995; Zekri et al. 2003; Kowalewski et al. 2006; Zargari et al. 2010). Al-Sulaimani et al. (2012) concluded that the ability of the biosurfactant used in this study to alter the wettability of rocks and surfaces is one of the mechanisms for enhancing oil recovery.

\section{Materials and methods}

\subsection{Biosurfactant production and extraction}

The procedure for bacterial growth and biosurfactant production is described in previous studies (Al-Sulaimani et al. 2010, 2011a, b). Briefly, the Bacillus subtilis strain W19 was grown in a minimal media (Table 1) containing $2 \%$ (w/v) glucose and incubated for $16 \mathrm{~h}$ at $40{ }^{\circ} \mathrm{C}$ and at 
Table 1 Composition of the production minimal medium

\begin{tabular}{ll}
\hline Composition & Concentration, g/L \\
\hline Glucose & 20.0 \\
$\mathrm{NH}_{4} \mathrm{NO}_{3}$ & 4.002 \\
$\mathrm{KH}_{2} \mathrm{PO}_{4}$ & 4.083 \\
$\mathrm{Na}_{2} \mathrm{HPO}_{4}$ & 7.119 \\
$\mathrm{MgSO}_{4}$ & 0.197 \\
$\mathrm{CaCl}_{2}$ & 0.00077 \\
$\mathrm{FeSO}_{4} \cdot 7 \mathrm{H}_{2} \mathrm{O}$ & 0.0011 \\
$\mathrm{MnSO}_{4} \cdot 4 \mathrm{H}_{2} \mathrm{O}$ & 0.00067 \\
$\mathrm{Na}_{2}-\mathrm{EDTA}$ & 0.00148 \\
\hline
\end{tabular}

$160 \mathrm{rpm}$. The bacterial cells were separated from the broth by centrifuging at $10,000 \mathrm{rpm}$ for $20 \mathrm{~min}$ at $20{ }^{\circ} \mathrm{C}$ in a high speed centrifuge (Beckman, USA, JLA 16.250 rotor).

For biosurfactant extraction, the cell-free broth was concentrated by a precipitation method (Youssef et al. $2007 \mathrm{a}, \mathrm{b})$. The precipitated biosurfactant was collected by centrifuging at $10,000 \mathrm{rpm}$, and finally, biosurfactant powder was obtained by spray drying following a standardized protocol at $160-100{ }^{\circ} \mathrm{C}$ using a Mini spray dryer (Buchi, Switzerland), as previously reported by $\mathrm{Al}-\mathrm{Su}-$ laimani et al. (2010; 2011a) .

\subsection{Rock and fluid samples}

Core plugs from a Middle East heavy oil field were used in coreflood experiments (Table 2). They are heterogeneous and consolidated (i.e., they do not produce fines). On average, the core plugs are $5.17 \mathrm{~cm}$ long with a diameter of $3.75 \mathrm{~cm}$. In order to understand better their mineralogy, XRD analyses were conducted on core plugs No. 4 and 7 and their mineral compositions are listed in Table 3. The salinity of formation water was between $7 \%$ and $9 \%$ and its chemical composition is shown in Table 4. Formation water was filter sterilized, prior to use, by a Millipore Filtration Unit with a membrane pore size of $0.45 \mu \mathrm{m}$. Original crude oil from the Middle East heavy oil field was used to saturate core samples. The characteristics of the crude oil are given in Table 5. The chemical surfactant used in this work is ethoxylated sulfonate, S-8B, kindly provided by a local oil company (active concentration of $\sim 23.9 \%$ ).

\subsection{Coreflood experiments}

Eleven core plugs obtained from the Middle East heavy oil field were used in coreflood experiments. Formation brine and crude oil used in all experiments were obtained from the same field (characteristics of crude oil are shown in Table 5). Initially, the core was cleaned using the Soxhlet extraction method where chloroform and methanol were solvents used as an azeotropic mixture in the proportion of 75:25. These solvents are constantly evaporated and condensed. The condensed solvent passed through the core sample removing all the oil and any other soluble material from the core before returning back for another cycle. This process was repeated until a clear color solvent was observed.

After cleaning, the core was dried at $65{ }^{\circ} \mathrm{C}$ for $24 \mathrm{~h}$ before use. The core was evacuated and then saturated with filtered formation brine for $24 \mathrm{~h}$ in a vacuum desiccator and the pore volume (PV) was determined using the dry and wet weights of the core. The core was then flooded with oil at $6 \mathrm{~cm}^{3} / \mathrm{h}$ until no more water was produced to establish residual water saturation. The oil initially in place (OIIP) was determined which was indicated by the volume of water displaced. After that, the core was subjected to hot waterflood at $6 \mathrm{~cm}^{3} / \mathrm{h}$ until no further oil was produced. The residual oil saturation to hot water was then calculated by measuring the amount of oil produced from the hot waterflood. Then, the chemical surfactant or the cell-free

Table 2 Properties of core plugs used in this study

\begin{tabular}{lllllll}
\hline Core No. & Length, $\mathrm{cm}$ & Diameter, $\mathrm{cm}$ & Porosity, $\%$ & Pore volume, $\mathrm{cm}^{3}$ & Liquid permeability, mD & Initial wettability \\
\hline 1 & 4.85 & 3.75 & 23.0 & 12.30 & 144 & Oil wet \\
2 & 5.25 & 3.75 & 22.8 & 13.20 & 162 & Oil wet \\
3 & 4.85 & 3.60 & 30.1 & 14.84 & 173 & Oil wet \\
4 & 4.85 & 3.60 & 26.8 & 13.24 & 149 & Oil wet \\
5 & 5.47 & 3.80 & 23.0 & 14.27 & 152 & Oil wet \\
6 & 5.19 & 3.82 & 22.9 & 13.64 & 159 & Oil wet \\
7 & 5.35 & 3.78 & 23.0 & 13.81 & 151 & Oil wet \\
8 & 5.40 & 3.65 & 23.0 & 13.00 & 163 & Oil wet \\
9 & 4.40 & 3.90 & 23.0 & 12.10 & 158 & Oil wet \\
10 & 5.10 & 3.70 & 23.0 & 12.60 & 149 & Oil wet \\
11 & 5.20 & 3.90 & 23.0 & 14.30 & Oil wet \\
\hline
\end{tabular}


Table 3 Mineral composition of core plugs determined by

$\mathrm{X}$-ray diffraction

\begin{tabular}{lllllll}
\hline Core No. & Quartz, $\%$ & Albite, $\%$ & Orthoclase, $\%$ & Calcite, $\%$ & Muscovite, $\%$ & Clinochlore, $\%$ \\
\hline 4 & 68.7 & 16.1 & 12.2 & 0.3 & 1.2 & 1.4 \\
7 & 67.4 & 16.4 & 11.2 & 0.5 & 1.0 & 3.5 \\
\hline
\end{tabular}

Table 4 Composition of formation water

\begin{tabular}{lc}
\hline Component & Concentration, $\mathrm{kg} / \mathrm{m}^{3}$ \\
\hline Sodium & 25.08 \\
Calcium & 3.76 \\
Magnesium & 0.878 \\
Iron & 0.045 \\
Chloride & 47.72 \\
Sulfate & 0.247 \\
Carbonate & 0 \\
Bicarbonate & 0.079 \\
\hline
\end{tabular}

Table 5 Middle East heavy oil characteristics

\begin{tabular}{ll}
\hline Characteristics & Values \\
\hline Density at $15{ }^{\circ} \mathrm{C}, \mathrm{kg} / \mathrm{L}$ & 0.98 \\
Specific gravity @ 60/60 ${ }^{\circ} \mathrm{F}$ & 0.98 \\
API gravity @ $60{ }^{\circ} \mathrm{F},{ }^{\circ} \mathrm{API}$ & 13.5 \\
Pour point, ${ }^{\circ} \mathrm{F}$ & 62 \\
Flash point, ${ }^{\circ} \mathrm{F}$ & $\geq 240$ \\
Kinematic viscosity @ $140{ }^{\circ} \mathrm{F}, \mathrm{cST}$ & 2500 \\
Total salts, ppm & 80,000 \\
\hline
\end{tabular}

supernatant (biosurfactant broth) was injected as a tertiary recovery stage and extra oil recovery was determined. In another set of experiments, the biosurfactant and chemical surfactant mixture solutions were injected at different ratios of $25: 75,50: 50$, and $75: 25$ of biosurfactant to chemical surfactant, respectively, all at a final concentration of $0.25 \%(\mathrm{w} / \mathrm{v})$. The effluent was collected at regular time intervals in 12 - or $20-\mathrm{mL}$ containers and the volumes of effluent were measured.

All corefloods were conducted at $90{ }^{\circ} \mathrm{C}$ to mimic the average reservoir temperature of the field of interest. Flow experiments were performed at the coreflood rig housed at Sultan Qaboos University (Fig. 1). The coreflood rig is composed of following components:

1) High-pressure Quizix pumps (up to 10,000 psi working pressure). These pumps are housed inside the oven. They can be used for permeability measurements.

2) A specially designed core holder is placed inside the oven to carry out tests at the reservoir temperature. Working pressure of the core holder is 10,000 psi and it can sustain up to $250{ }^{\circ} \mathrm{C}$.

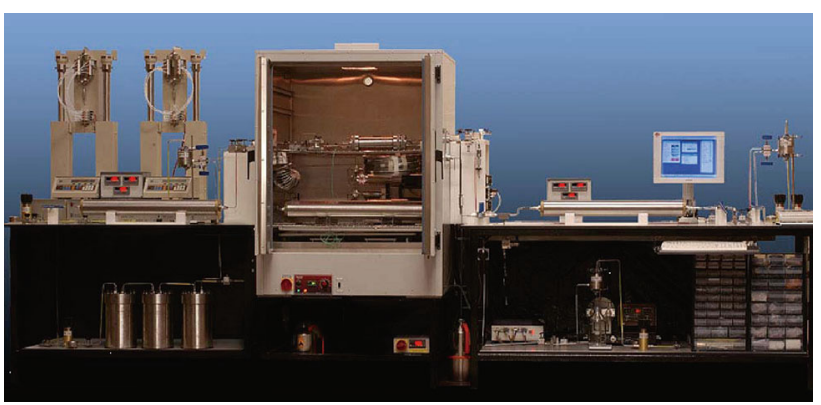

Fig. 1 Core flow set up at the Sultan Qaboos University

3) Also housed inside the oven are Hastelloy tubing coils for the temperature equilibrium while injecting fluids. The coil can hold up to $600 \mathrm{~mL}$ of fluid. All the fittings inside the oven are acid-resistant Hastelloy fittings.

4) Two twin Isco pumps which have a working pressure of $7500 \mathrm{psi}$ and a flow rate ranging from 0.001 to $50 \mathrm{~mL} / \mathrm{min}$. The pumps are calibrated beforehand and found to be producing the expected rate to within $0.1 \%$.

5) Two high-pressure accumulators.

6) Back pressure regulator.

7) Data-logging system.

Apart from the above-mentioned major parts, the system is equipped with high precision pressure and differential pressure transducers. Besides, there is a high-pressure nitrogen gas compressor (4500 psi) used to pressurize the system to the reservoir condition.

\section{Results and discussion}

Worldwide petroleum companies are struggling to develop new economical technologies to recover heavy oil from maturing on-shore and off-shore oil fields. Among different technologies currently used, miscible gas like $\mathrm{CO}_{2}$ injection, steam injection, and use of chemical surfactants are quite successful. There are certain issues related to availability and cost-effectiveness for gas injection or steam injection; thus, chemical surfactants are preferred for EOR operations. Usage of chemical surfactants also has its pros and cons: it is effective in enhancing the oil recovery but is not so environmentally friendly and comparatively costly. Biosurfactants can be an environmentally friendly and an 
equally effective alternative to its chemical counterpart. We used chemical surfactant and biosurfactant individually or as a mixture, for their potential in enhancing heavy oil recovery from core plugs taken from the Middle East heavy oil field.

\subsection{Core, fluids, chemical surfactant, and biosurfactant properties}

Core plugs used contained mainly quartz (38\%-67\%), and remainder was other components (Table 3). The oil used was very heavy crude with $13.5^{\circ}$ API and $2500 \mathrm{cST}$ viscosity. The chemical surfactant was ethoxylated sulfonate and the biosurfactant was a lipopeptide, produced in our laboratory. The chemical surfactant (CS) and biosurfactant (BS) reduced brine/oil IFT values to 3.24 and 3.97 $\mathrm{mN} / \mathrm{m}$, respectively, from $36 \mathrm{mN} / \mathrm{m}$. When CS and BS were mixed at different proportions, the brine/oil IFT values were reduced to $3.2 \mathrm{mN} / \mathrm{m}$ (CS:BS; 75:25), 3.11 $\mathrm{mN} / \mathrm{m}$ (CS:BS; 50:50), and $4 \mathrm{mN} / \mathrm{m}$ (CS:BS; 25:75), respectively. Thus, we observed a slight reduction in IFT with a 50:50 CS + BS mixture, compared to individual surfactants. The biosurfactant used in this study also showed the ability to change the wettability of sandstone rock surfaces, thus altering it from oil-wet to water-wet (Al-Sulaimani et al. 2012).

\subsection{Coreflood experiments using chemical surfactant and biosurfactant}

Coreflood experiments were carried out to recover heavy oil, as initially flooded by hot water (as the secondary mode) followed by either chemical surfactant or biosurfactant individually and as a mixture (the tertiary mode). Tables 6, 7 and 8 summarize the initial water and oil saturations, residual oil saturations after the injection of hot water, chemical surfactant, biosurfactant, and mixtures of both surfactants, where it can be observed that the biosurfactant injection recovered more oil compared to chemical surfactant only injection (Tables 6 and 7), which was around $1.4 \%-18.5 \%$ over the residual oil saturation $\left(S_{\text {or }}\right)$, whereas the mixture of the biosurfactant and the chemical surfactant at different ratios gave the highest recovery of $27 \%-34 \%$ over $S_{\text {or }}$ (Table 8 ).

Enhancement of oil recovery from Berea sandstone cores treated with cell-free metabolites from a surfactantproducing strain, Bacillus $s p$. JF-2, was reported by Thomas et al. (1993). Joshi et al. (2015) reported additional $37.1 \%$ of heavy oil from Berea sandstone cores at $80{ }^{\circ} \mathrm{C}$ was achieved using a lipopeptide-type of biosurfactant. Previous studies reported that biosurfactants could potentially be used in conjunction with synthetic surfactants to provide more cost-effective enhanced oil recovery and subsurface remediation (Youssef et al. 2007a, b). They reported that the activity of biosurfactants depends on their structural components where the 3-hydroxy fatty acid composition of lipopeptides is very important for the biosurfactant activity. Youssef et al. (2007a, b) manipulated the biosurfactant activity by changing the fatty acid composition, knowing the relationship to hydrophobicity/hydrophilicity, of the mixtures with different biosurfactants and synthetic surfactants and achieved an ultra-low IFT. So, it was hypothesized that the activity of the biosurfactant used in this study was enhanced when mixed with the chemical surfactant. Probably due to chemical interactions between the surface charges of the two surfactants and the synergetic effect, the enhancement in oil recovery was greater when the two surfactants were used as a mixture, rather than alone. Lu et al. (2014c) reported that for oils with a high alkane carbon number, surfactants with very large hydrophobes are needed to obtain ultra-low IFT and to reduce the residual oil saturation to nearly zero. They reported new classes of large-hydrophobe surfactants developed for chemical EOR, where both the sulfates and carboxylates were tailored to specific reservoir conditions and oils by adjusting the number of ethylene oxide (EO) or propylene oxide $(\mathrm{PO})$ groups in the surfactant.

Figures 2, 3 and 4 show cumulative oil recoveries of the chemical surfactant flooding, biosurfactant flooding, and mixtures of both following hot water injection. Figure 5 shows the best of the 3 flooding types following hot water injection. All the experiments were carried out at $0.25 \%$ $(w / v)$ concentration of chemical surfactant or biosurfactant. The results revealed that $1.4 \%-11 \%$ of residual oil was produced by the pure chemical surfactant injection (Fig. 2),

Table 6 Residual oil saturations and \% of heavy oil recovery enhancement following hot water injection and chemical surfactant injection

\begin{tabular}{lllllc}
\hline $\begin{array}{l}\text { Core } \\
\text { No. }\end{array}$ & $\begin{array}{l}\text { Initial water } \\
\text { saturation, } \%\end{array}$ & $\begin{array}{l}\text { Initial oil } \\
\text { saturation, } \%\end{array}$ & $\begin{array}{l}\text { Residual oil saturation after hot } \\
\text { water injection, \% }\end{array}$ & $\begin{array}{l}\text { Residual oil saturation after chemical } \\
\text { surfactant injection, \% }\end{array}$ & $\begin{array}{l}\% \text { of heavy oil recovery } \\
\text { enhancement }\end{array}$ \\
\hline 1 & 11.0 & 89.0 & 91.5 & 89.0 & 2.5 \\
3 & 10.5 & 89.5 & 83.0 & 75.0 & 8.0 \\
5 & 12.0 & 88.0 & 95.8 & 94.4 & 1.4 \\
7 & 10.0 & 90.0 & 57.0 & 46.0 & 11.0 \\
\hline
\end{tabular}


Table 7 Residual oil saturations and \% of heavy oil recovery enhancement following hot water injection and biosurfactant injection

\begin{tabular}{lllllc}
\hline $\begin{array}{l}\text { Core } \\
\text { No. }\end{array}$ & $\begin{array}{l}\text { Initial water } \\
\text { saturation, } \%\end{array}$ & $\begin{array}{l}\text { Initial oil } \\
\text { saturation, } \%\end{array}$ & $\begin{array}{l}\text { Residual oil saturation after hot } \\
\text { water injection, } \%\end{array}$ & $\begin{array}{l}\text { Residual oil saturation after } \\
\text { biosurfactant injection, \% }\end{array}$ & $\begin{array}{l}\% \text { of heavy oil recovery } \\
\text { enhancement }\end{array}$ \\
\hline 2 & 13.0 & 87.0 & 83.7 & 76.9 & 6.8 \\
4 & 12.5 & 87.5 & 76.0 & 67.0 & 9.0 \\
6 & 10.0 & 90.0 & 52.0 & 33.5 & 18.5 \\
8 & 11.0 & 89.0 & 62.0 & 51.0 & 11.0 \\
\hline
\end{tabular}

Table 8 Residual oil saturations and \% of heavy oil recovery enhancement following hot water injection and chemical/biosurfactant mixture injection

\begin{tabular}{lllllll}
\hline $\begin{array}{l}\text { Core } \\
\text { No. }\end{array}$ & $\begin{array}{l}\text { Initial water } \\
\text { saturation, } \\
\%\end{array}$ & $\begin{array}{l}\text { Initial oil } \\
\text { saturation, } \\
\%\end{array}$ & $\begin{array}{l}\text { Residual oil saturation } \\
\text { after hot water } \\
\text { injection, } \%\end{array}$ & $\begin{array}{l}\text { Residual oil saturation after chemical } \\
\text { surfactant/biosurfactant mixture } \\
\text { injection, } \%\end{array}$ & $\begin{array}{l}\text { Biosurfactant to } \\
\text { chemical } \\
\text { surfactant ratio }\end{array}$ & $\begin{array}{l}\% \text { of heavy oil } \\
\text { recovery } \\
\text { enhancement }\end{array}$ \\
\hline 9 & 13.0 & 87.0 & 67.0 & 36.0 & $75: 25$ & 31 \\
10 & 12.5 & 87.5 & 50.0 & 16.0 & $50: 50$ & 34 \\
11 & 10.0 & 90.0 & 71.0 & 44.0 & $25: 75$ & 27 \\
\hline
\end{tabular}

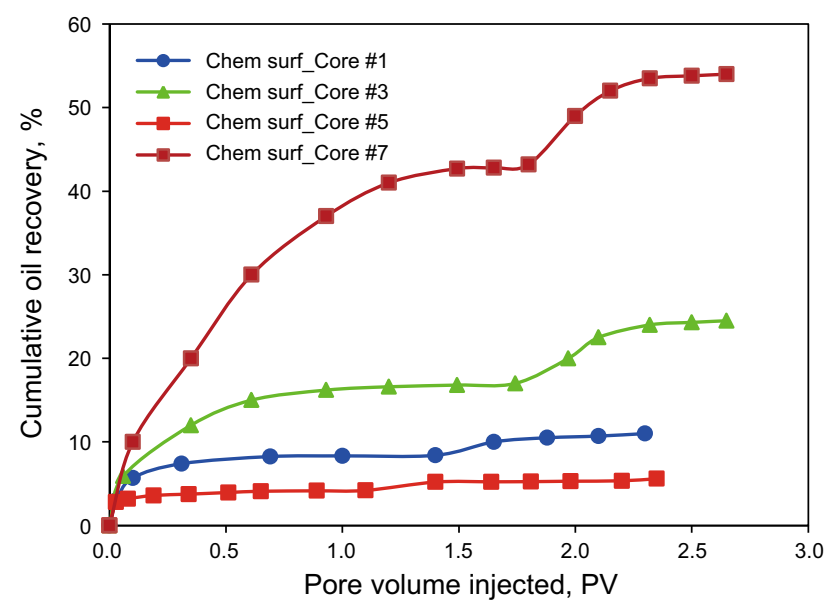

Fig. 2 Cumulative oil recovery via hot water injection (injection was continued until no more oil was recovered) followed by injecting chemical surfactant

while the production increased to $6.8 \%-18.5 \%$ of residual oil when the biosurfactant was injected (Fig. 3). However, it was interesting to note that the performance was improved when mixing the biosurfactant with the chemical surfactant at all ratios tested compared to injecting pure solutions. Recovery up to $34 \%$ of residual oil was produced when mixing both surfactants in a ratio of 50:50, while the mixture of $75 \%$ biosurfactant and $25 \%$ chemical surfactant yielded an increased production of $31 \%$. The least production by the mixed surfactants was in a ratio of 25:75 of the biosurfactant to the chemical surfactant where the recovery was estimated to be $27 \%$ (Fig. 4). However, it is still higher than the production obtained by injecting the biosurfactant or chemical surfactant solutions alone (Tables 6, 7 and 8). Nguyen et al.

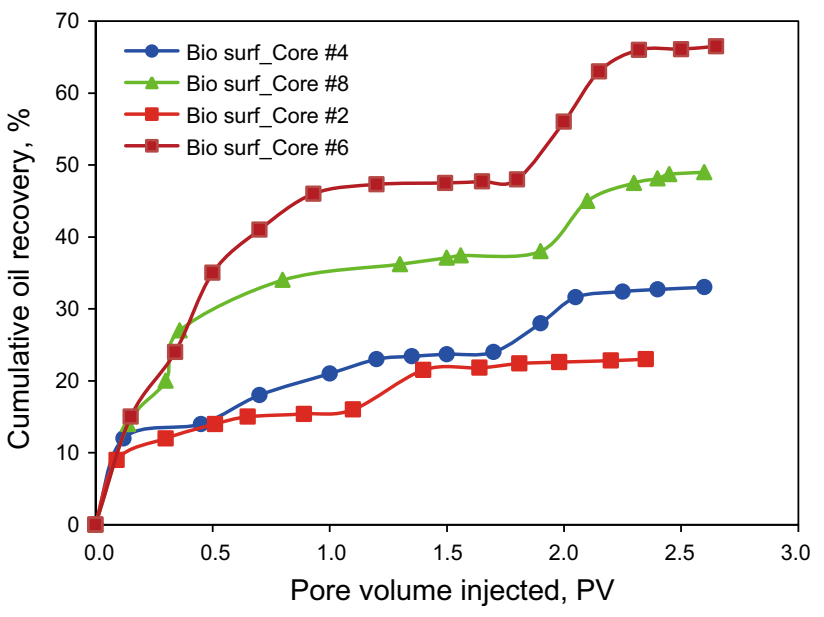

Fig. 3 Cumulative oil recovery via hot water injection (injection was continued until no more oil was recovered) followed by injecting biosurfactant

(2008) investigated the efficiency of a mixture of rhamnolipid biosurfactant and synthetic surfactant for improving the interfacial activity of the surfactant system against several light non-aqueous-phase liquids (LNAPLs). They reported that the rhamnolipid biosurfactant was quite hydrophilic relative to the hydrocarbons tested and that mixing it with more hydrophobic synthetic surfactants enhanced the interfacial activity of the rhamnolipid against those hydrocarbons. Torres et al. (2011) reported the performance of three biosurfactants (of bacterial and vegetal origin) in comparison to different synthetic surfactants (cationic, anionic, non-ionic, and zwitterionic) for potential use in EOR applications. They also reported that biosurfactants have potential for EOR and analyzing the surface properties (ST and IFT) of pure surfactants and mixtures, 


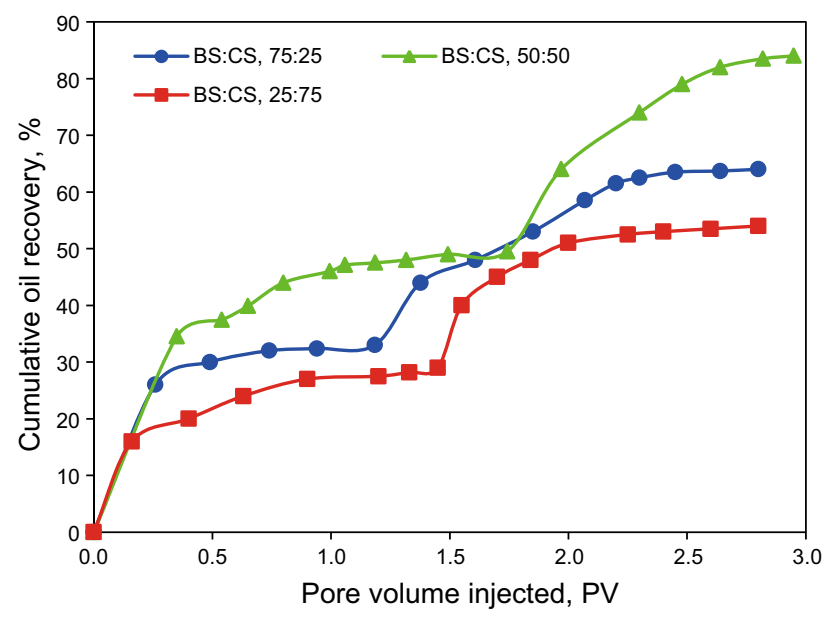

Fig. 4 Cumulative oil recovery via hot water injection (injection was continued until no more oil was recovered) followed by injecting mixtures of chemical surfactant and biosurfactant. Cores \# 9, 10, and 11 were used in these tests

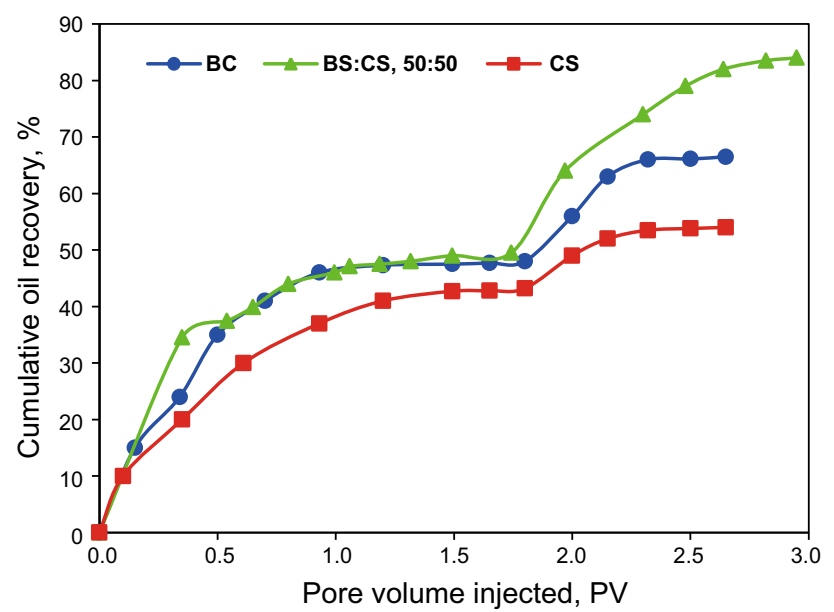

Fig. 5 Comparison of maximum cumulative oil recovery via hot water injection (injection was continued until no more oil was recovered) followed by chemical surfactant, biosurfactant, or mixtures of both. Cores \# 6, 7, and 10 were used in these tests

together with other tests will give important information regarding the behavior of surfactants under oil-wet conditions. These assessments will lead to the selection of the right surfactant(s) and mixtures for different oil field applications.

Youssef et al. (2007a, b) reported that biosurfactant and synthetic surfactant mixtures could be formulated to provide appropriate hydrophobic/hydrophilic conditions necessary to reduce the IFT against NAPLs, and that such mixtures produced synergism that made them more effective than individual surfactants alone. They reported that mixtures of lipopeptide biosurfactants with the hydrophobic synthetic surfactant were able to produce low IFT against hexane and decane as compared to an individual surfactant alone. When we mixed the biosurfactant and the chemical surfactant in mode a ratio of 50:50, a slight reduction in IFT was observed, as compared to individual surfactants. This might explain part of the increase in residual oil recovery. Other recovery mechanisms are expected by the nature of biosurfactant, such as wettability alteration. Al-Sulaimani et al. (2012) conducted experiments which proved the ability of the biosurfactant used in this study to change the wettability of sandstone rock surfaces. The influence of biosurfactants on wettability was studied by contact angle measurements, atomic force microscopy (AFM) technique on few-layer graphene (FLG) surfaces, and Amott wettability tests. It was reported that the biosurfactant altered the wettability of sandstone rocks from oil-wet to more water-wet. Thus, it was concluded that the wettability alteration by the biosurfactant is one of the major mechanisms of microbial enhanced oil recovery. The combined effects of the reduction in IFT and wettability alteration using surfactants have also been discussed in the literature (Anderson 1986; Alveskog et al. 1998; Austad and Standnes 2003; Hirasaki and Zhang 2004; Kowalewski et al. 2006; Zhang and Austad 2006; Lu et al. 2014b). Kowalewski et al. (2006) reported that changes in wetting properties are dependent on the initial wetting conditions where an initially oil-wet system can result in more water-wet conditions and vice versa. $\mathrm{Lu}$ et al. (2014b) reported a surfactant formulation (a novel large-hydrophobe alkoxy carboxylate surfactant and an internal olefin sulphonate co-surfactant) developed for carbonate reservoirs under high salinity and temperature, where it reduced the IFT to ultra-low values and also altered the wettability of the rock toward more favorable water-wet conditions, leading to enhanced oil recovery.

\subsection{Coreflood experiment using a mixture of chemical and biosurfactant in the secondary or tertiary mode}

As revealed from the above results, the maximum reduction in the residual oil saturation was achieved when mixing the chemical surfactant and the biosurfactant in a ratio of 50:50. This surfactant mixture was selected for testing whether starting the injection with the surfactant solution rather than waterflooding is more effective (surfactant injection at the secondary mode). Core plug No. 10 was used in this test. Figure 6 presents a comparison between the secondary (direct chemical surfactant/biosurfactant mixture, without hot water flooding) and tertiary modes (hot water followed by the chemical surfactant/ biosurfactant mixture) of surfactant injection. Results show that compared to the tertiary mode, the secondary mode resulted in higher breakthrough recovery by $7 \%$ (Fig. 6). However, the ultimate oil recovery in the secondary mode 


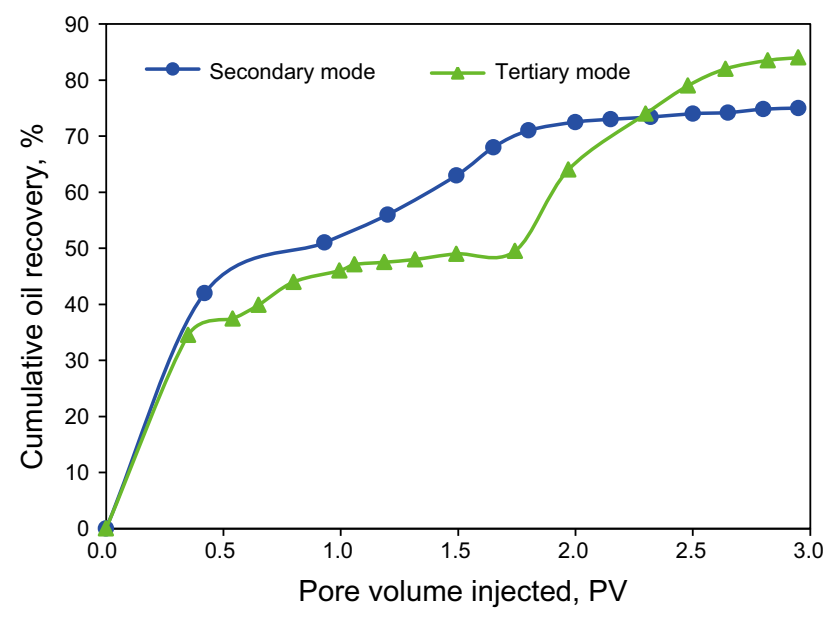

Fig. 6 Comparison of cumulative oil recovery obtained by injecting the 50:50 of biosurfactant to chemical surfactant mixture in the secondary and tertiartry recovery modes. Core \# 10 was used in these tests

is $9 \%$ less than that in the tertiary mode. This may be due to the fact that in the secondary mode, the surfactant should improve the macroscopic sweep efficiency besides the microscopic sweep efficiency, whereas in the tertiary mode, the microscopic sweep efficiency is what matters mainly. In other words, the surfactant mixture injected in the secondary mode improved (a) the volumetric sweep of the injection fluid, (b) the displacement efficiency of the injection fluid in the rock volume that is swept, and (c) the capture of the displaced oil at the core sample outlet, whereas in the tertiary mode when the surfactant mixture was injected after hot water injection, it was mainly utilized for improving the displacement efficiency of the injection fluid in the rock volume that is swept. Because of viscous fingering and incomplete areal sweepout (caused by rock pore structure, e.g., dead-end pores filled with oil), the volumetric sweepout of the reservoir volume is always much less than $100 \%$. Additionally, not all the oil displaced from the swept areas is captured at the core sample outlet. Babadagli et al. $(2002 ; 2005)$ reported that when the surfactant solution is injected as a secondary recovery fluid, the critical issue is the better penetration of the fluid provided by less emulsion, more water wettability, and less adsorption. On the other hand, when the surfactant is injected as a tertiary recovery fluid, the critical issue is the reduced IFT between oil and water and oil and rock rather than a better penetration causing a better sweep. This is in line with our observations.

Thus, it was concluded that it is not effective and not feasible to inject the surfactant mixture directly at the secondary recovery stage. This is valid when viscous forces dominant the flood in the reservoir rock matrix. If the fractures dominate the flow, the recovery mechanism will change (Babadagli et al. 2005).

\section{Conclusions}

(1) Injecting the chemical surfactant and the biosurfactant following hot water injection (the tertiary recovery mode) reduces the heavy oil residual saturation by the maximum of $11 \%$ and $18.5 \%$, respectively.

(2) Interestingly, the reduction in residual oil saturation after hot water flood increases to $34 \%$ when the chemical surfactant is mixed with the biosurfactant in a ratio of 50:50. This is attributed to the synergetic effect between the two surfactants.

(3) Compared to the tertiary mode, the secondary mode resulted in higher breakthrough recovery but lower ultimate oil recovery. This is maybe due to the fact that in the secondary mode, the surfactant should improve the macroscopic sweep efficiency (volumetric sweep of the injection fluid and capture of the displaced oil at the core sample outlet) rather than the microscopic sweep efficiency (displacement efficiency of the injection fluid in the rock volume that is swept), whereas in the tertiary mode, the microscopic sweep efficiency is what matters mainly.

(4) If viscous forces dominant the flood in the reservoir rock matrix like the cases investigated in this study, it is not rewarding to inject the chemical surfactant/ biosurfactant mixture as the secondary recovery stage.

In retrospect, the results presented in this work demonstrate the high potential of injecting a mixture of biosurfactant and chemical surfactant following hot water injection to reduce heavy oil residual saturation. For field scale applications, however, it is imperative to conduct a study to determine the range of conditions at which the proposed technology can be successfully applied.

Acknowledgments Authors acknowledge His Majesty Research Fund (SR/SCI/BIOL/08/01), Sultan Qaboos University, Oman and the Petroleum Development of Oman (CR/SCI/BIOL/07/02) for the research grants. The authors would like also to gratefully thank Mr. Nayyer Afzal, Mr. Adel Al-Rubkhi, and Mr. Ike Sirono for their technical assistance with coreflood experiments.

Open Access This article is distributed under the terms of the Creative Commons Attribution 4.0 International License (http://crea tivecommons.org/licenses/by/4.0/), which permits unrestricted use, distribution, and reproduction in any medium, provided you give appropriate credit to the original author(s) and the source, provide a 
link to the Creative Commons license, and indicate if changes were made.

\section{References}

Al-Bahry S, Elshafie A, Al-Wahaibi Y, et al. Microbial consortia in Oman oil fields: a possible use in enhanced oil recovery. J Microbiol Biotechnol. 2013a;23(1):106-17. doi:10.4014/jmb. 1204.04021.

Al-Bahry SN, Al-Wahaibi Y, Elshafie A, et al. Biosurfactant production by Bacillus subtilis B20 using date molasses and its application in enhanced oil recovery. Int Biodeterior Biodegrad. 2013b;81:141-6. doi:10.1016/j.ibiod.2012.01.006.

Al-Sulaimani H, Al-Wahaibi Y, Al-Bahry S, et al. Experimental investigation of biosurfactants produced by Bacillus species and their potential for MEOR in Omani Oil Field. In: Oil and gas West Asia, 11-13 April, Muscat; 2010. doi:10.2118/129228-MS.

Al-Sulaimani H, Al-Wahaibi Y, Al-Bahry S, et al. Optimization and partial characterization of biosurfactant produced by Bacillus species and their potential for ex-situ enhanced oil recovery. SPE J. 2011a;16(3):672-82. doi:10.2118/129228-PA.

Al-Sulaimani H, Joshi S, Al-Wahaibi Y, et al. Microbial biotechnology for enhancing oil recovery: current developments and future prospects. Invited Rev Biotechnol Bioinform Bioeng J. 2011b;1(2):147-58.

Al-Sulaimani H, Al-Wahaibi Y, Al-Bahry SN, et al. Residual oil recovery through injection of biosurfactant, chemical surfactant and mixtures of both under reservoir condition: induced wettability and interfacial tension effects. SPE Reserv Eval Eng. 2012;15(2):210-7. doi:10.2118/158022-PA.

Alveskog PL, Holt T, Torsaeter O. The effect of surfactant concentration on the Amott wettability index and residual oil saturation. J Pet Sci Eng. 1998;20:247-52. doi:10.1016/S09204105(98)00027-8

Anderson WG. Wettability literature survey- part 2: wettability measurements. J Pet Technol. 1986;281:1246-62. doi:10.2118/ 13933-PA

Aoudia M, Al-Shibli M, Al-Kasimi L, et al. Novel surfactants for ultralow interfacial tension in a wide range of surfactant concentration and temperature. J Surfactants Deterg. 2006;9(3):287-93. doi:10.1007/s11743-006-5009-9.

Austad T, Standnes DC. Spontaneous imbibitions of water into oilwet carbonates. J Pet Sci Eng. 2003;39:363-7. doi:10.1016/ S0920-4105(03)00075-5.

Babadagli T. Dynamics of capillary imbibition when surfactant, polymer and hot water are used as aqeous phase for oil recovery. J Colloids Interface Sci. 2002;246(1):203-13. doi:10.1006/jcis. 2001.8015 .

Babadagli T, Al-Bemani A, Boukadi F, Al-Maamari R. A laboratory feasibility study of dilute surfactant injection for the Yibal field, Oman. J Pet Sci Eng. 2005;48(1):37-52. doi:10.1016/j.petrol. 2005.04.005.

Curbelo FD, Santanna VC, Neto EL, et al. Adsorption of nonionic surfactants in sandstones. Colloids Surf A. 2007;293:1-4. doi:10. 1016/j.colsurfa.2006.06.038.

Daoshan L, Shouliang L, Yi L, Demin W. The effect of biosurfactant on the interfacial tension and adsorption loss of surfactant in ASP flooding. Colloids Surf A. 2004;244:53-60. doi:10.1016/j. colsurfa.2004.06.017.

Gautam KK, Tyagi VK. Microbial surfactants: a review. J Oleo Sci. 2005;55(4):155-66. doi:10.5650/jos.55.155.

Ghojavand H, Vahabzadeh F, Roayaei E, Shahrakai A. Production and properties of a biosurfactant obtained from a member of the
Bacillus subtilis group (PTCC 1696). J Colloid Interface Sci. 2008;324:172-6. doi:10.1016/j.jcis.2008.05.001.

Hazra C, Kundu D, Ghosh P, et al. Screening and identification of Pseudomonas aeruginosa $\mathrm{AB} 4$ for improved production, characterization and application of a glycolipid biosurfactant using low-cost agro-based raw materials. J Chem Technol Biotechnol. 2011;86:185-98. doi:10.1002/jctb.2480.

Hirasaki G, Zhang DL. Surface chemistry of oil recovery from fractured, oil-wet, carbonate formation. SPE J. 2004;9(2):151-62. doi:10.2118/80988-MS

Iglauer S, Wu Y, Shuler P, et al. New surfactant classes for enhanced oil recovery and their tertiary oil recovery potential. J Pet Sci Eng. 2010;71:23-9. doi:10.1016/j.petrol.2009.12.009.

Joshi S, Bharucha $\mathrm{C}$, Jha $\mathrm{S}$, et al. Biosurfactant production using molasses and whey under thermophilic conditions. Bioresour Technol. 2008;99(1):195-9. doi:10.1016/j.biortech.2006.12. 010.

Joshi SJ, Desai AJ. Bench-scale production of biosurfactants and their potential in ex-situ MEOR application. Soil Sediment Contam. 2013;22(6):701-15. doi:10.1080/15320383.2013.756450.

Joshi SJ, Geetha SJ, Desai AJ. Characterization and application of biosurfactant produced by Bacillus licheniformis R2. Appl Biochem Biotechnol. 2015;177:346-61. doi:10.1007/s12010015-1746-4.

Kowalewski E, Rueslatten I, Steen KH, et al. Microbial improved oil recovery-bacterial induced wettability and interfacial tension effects on oil production. J Pet Sci Eng. 2006;52:275-86. doi:10. 1016/j.petrol.2006.03.011.

Lee S, Kim S, Park I, et al. Isolation and structural analysis of bamylocin A, novel lipopeptide from Bacillus amyloliquefaciens LP03 having antagonistic and crude oil-emulsifying activity. J Arch Microbiol. 2007;188:307-12. doi:10.1007/s00203-0070250-9.

Lu J, Britton C, Solairaj S, et al. Novel large-hydrophobe alkoxy carboxylate surfactants for enhanced oil recovery. SPE J. 2014a;19(6):1024-34. doi:10.2118/154261-PA.

Lu J, Goudarzi A, Chen P, et al. Enhanced oil recovery from hightemperature, high-salinity naturally fractured carbonate reservoirs by surfactant flood. J Pet Sci Eng. 2014b;124:122-31. doi:10.1016/j.petrol.2014.10.016.

Lu J, Liyanage PJ, Solairaj S, et al. New surfactant developments for chemical enhanced oil recovery. J Pet Sci Eng. 2014c;120:94-101. doi:10.1016/j.petrol.2014.05.021.

$\mathrm{Lu}$ J, Weerasooriya UP, Pope GA. Investigation of gravity-stable surfactant floods. Fuel. 2014d;124:76-84. doi:10.1016/j.fuel.2014. 01.082 .

Makkar RS, Cameotra SS. Biosurfactant production by a thermophilic Bacillus subtilis strain. $\mathrm{J}$ Ind Microbiol Biotechnol. 1997;18:37-42. doi:10.1038/sj.jim.2900349.

Nguyen TT, Youssef NH, McInerney MJ, Sabatini DA. Rhamnolipid biosurfactant mixtures for environmental remediation. Water Res. 2008;42:1735-43. doi:10.1016/j.watres.2007.10.038.

Noudeh GD, Housaindokht M, Bazzaz BS. Isolation, characterization and investigation of surface hemolytic activities of a lipopeptide biosurfactant produced by Bacillus subtilis ATCC 6633. J Microbiol. 2005;43(3):272-6.

Portwood JT. A commercial microbial enhanced oil recovery technology: evaluation of 322 projects. In: SPE production operations symposium, January, Oklahoma; 1995. doi:10.2118/29518-MS.

Sayyouh MH, Al-Blehed MS. Effect of microorganisms on rock wettability. J Adhes Sci Technol. 1995;9:425-31. doi:10.1163/ $156856195 X 00365$.

Thomas CP, Bala GA, Duvall ML. Surfactant-based enhanced oil recovery mediated by naturally occurring microorganisms. SPE Reserv Eng. 1993;11:285-91. doi:10.2118/22844-PA. 
Torres L, Moctezuma A, Avendaño JR, et al. Comparison of bio-and synthetic surfactants for EOR. J Pet Sci Eng. 2011;76:6-11. doi:10.1016/j.petrol.2010.11.022.

Youssef N, Simpson DR, Duncan KE, et al. In situ biosurfactant production by Bacillus strains injected into a limestone petroleum reservoir. Appl Environ Microbiol. 2007a;73:1239-47. doi:10.1128/AEM.02264-06.

Youssef NH, Nguyen T, Sabatini DA, McInerney MJ. Basis for formulating biosurfactant mixtures to achieve ultralow interfacial tension values against hydrocarbons. J Ind Microbiol Biotechnol. 2007b;34(7):497-507. doi:10.1007/s10295-007-0221-9.

Zargari S, Ostvar S, Niazi A, Ayatollahi S. Atomic force microscopy and wettability study of the alteration of mica and sandstone by a biosurfactant-producing bacterium Bacillus thermodenitrificans. J Adv Microsc Res. 2010;5:1-6. doi:10.1166/jamr.2010.1036.
Zekri AY, Mamdouh TG, Almehaideb RA. Carbonate rocks wettability changes induced by microbial solution. In: SPE Asia Pacific oil and gas conference and exhibition, 15-17 April, Jakarta; 2003. doi:10.2118/80527-MS.

Zhang P, Austad T. Wettability and oil recovery from carbonates: effects of temperature and potential determining ions. Colloids Surf A. 2006;279:179-87. doi:10.1016/j.colsurfa.2006.01.009.

Zhu Y, Xu G, Gong H, et al. Production of ultra-low interfacial tension between crude oil and mixed brine solution of Triton X-100 and its oligomer Tyloxapol with cetyltrimethylammonium bromide induced by hydrolyzed polyacrylamide. Colloids Surfaces A: Physicochem Eng Aspects. 2009;332:90-7. doi:10. 1016/j.colsurfa.2008.09.012. 